\title{
Session T3H Work in Progress - Role of Faculty in Promoting Lifelong Learning: Initial Findings
}

\author{
John C. Chen, Susan M. Lord, Katharyn Nottis, Michael Prince, Candice Stefanou, Jonathan Stolk \\ jchen24@calpoly.edu, slord@sandiego.edu,knottis@bucknell.edu, prince@bucknell.edu, \\ cstefano@bucknell.edu, Jonathan.Stolk@olin.edu
}

\begin{abstract}
Calls for educational reform emphasize the need for student-centered learning approaches that foster lifelong learning. To be a lifelong learner includes characteristics consistent with those of self-directed learners, such as being curious, motivated, reflective, analytical, persistent, flexible, and independent. Instructor support of students' self-directed learning (SDL) development relies on understanding and balancing these factors in the classroom. Engineering educators play a critical role in influencing outcomes related to SDL through their design of courses that support students' transitions from controlled to autonomous learning behaviors. This study will examine a variety of engineering courses and pedagogical approaches. Each will be characterized using instructor course information, recorded observations of instructorstudent and student-student interactions, student and instructor responses to surveys, and focus groups. Finally, the students' capacity for SDL will be measured using the Motivated Strategies for Learning Questionnaire. This approach should provide for rich, contextualized descriptions of what instructors and learners do, how instructors and students relate to each other, and how students view their classrooms. This work-in-progress paper will describe our initial work in this multiyear study.
\end{abstract}

Index Terms - Lifelong learning, Autonomy support, Selfdirected learning.

\section{INTRODUCTION}

Calls for educational reform emphasize the need for studentcentered learning approaches that aid development of broader skills and attitudes such as a capacity for lifelong learning [1,2]. Engineering educators as well as ABET recognize that students' development of such a capacity is vital for their success in today's global and rapidly changing engineering environment $[1,2,3]$. However, the current emphasis - particularly in the engineering education community - seems to be on assessing students' lifelong learning abilities, rather than on understanding the relationship between instructor practices and lifelong learning outcomes.

The limited existing studies show no significant gains in undergraduate engineering students' capacity for SDL via traditional instruction [4,5]. However, nontraditional instructional practices such as problem-based learning are

978-1-4244-6262-9/10/\$26.00 C2010 IEEE more explicitly designed to develop student attitudes and skills relevant to SDL, and there is some literature support to suggest that these approaches are more effective at developing self-directed learners [6]. There remains, however, little empirical data on those factors that promote SDL amongst undergraduate engineering students, especially from carefully designed studies using validated instruments. This multiyear investigation seeks to fill that gap by conducting an observational study that examines a range of engineering environments, carefully characterizes instructor practices regarding support of student autonomy, and analyzes the relationship between classroom environments and proxies for lifelong learning such as SDL behaviors and attitudes

\section{ROLE OF INSTRUCTOR IN SELF-DIRECTED LEARNING}

Although much of the burden of developing SDL competence falls on students, instructors also play a critical role in effectively promoting individual SDL development both through their instructional choices and their interactions with students. Autonomy support is one such area in which different practices may yield different outcomes. Opportunities for individual choice, control, authority, and responsibility appear to be important elements in both the academic achievement and the psychological development of students.

Stefanou et al. [7] provided a framework for characterizing different types of autonomy support that may help develop students' self-directed learning, along with examples of specific instructor strategies. In this framework, Organizational Autonomy Support includes student choices that are primarily related to contextual factors (e.g., selection of team members) and behavioral factors (e.g., managing due dates). Procedural Autonomy Support includes choices related to students' intrinsic motivations (e.g., discussing their wants and displaying individual work), and some opportunities that connect motivational and cognitive strategies (e.g., selection of resources). The Cognitive Autonomy Support describes choices that relate directly to students' mental processes during learning (e.g., selfreflection on errors, consideration of multiple solutions and strategies). It is through this framework that we will evaluate the role of faculty in developing SDL behaviors.

\section{Methodology}

A variety of different undergraduate engineering course environments will be examined as part of this study. The

October 27 - 30, 2010, Washington, DC $40^{\text {th }}$ ASEE/IEEE Frontiers in Education Conference 
Session T3H

courses range from sophomore to senior level, include both lecture and laboratory settings, and provide a range of pedagogical strategies that emphasize active, collaborative, problem-based learning, and project-based learning. This study focuses on active learning environments since these have provided the most promising results to date for developing students' capacity for self-directed learning.

Although all of the classroom settings may be characterized as "active," the different courses present recognizable differences in the types and amounts of student choice and control, as well as differences in the classroom environment characterized in terms of student-student and student-faculty interactions in support of student autonomy. As such, these courses provide an opportunity to study the relationships between differences in autonomy support on the development of SDL-related competencies of motivation, student autonomy, and cognitive and metacognitive strategy use. We anticipate the different courses will provide wide variety in the type and level of organizational, procedural and cognitive student autonomy support.

A selection of class sessions for each of the instructors is being studied intensively through the lens of autonomysupportive practices. To do this, syllabi and classroom artifacts in the form of classroom assignments have been collected, selected class sessions are recorded, and the instructors completed a survey that measures personal epistemology. Students also completed a survey that measures the aspects of motivation, autonomy, and cognitive and metacognitive strategy use that are associated with SDL at the beginning of the semester and again at the end, and instructor-student and student-student interactions are recorded. At the completion of the course, the instructors are interviewed to discuss the choices they made in their course and focus groups of students are interviewed to discuss how those choices affected the variables of interest in this study.

A mixed-method approach is being used to examine how instructors support and facilitate student autonomy and other outcomes associated with SDL using the data gathered for courses in the 2009-2010 academic year. This includes:

- Characterizing the learning environment within the chosen engineering courses with respect to support of student autonomy and authority within the framework developed by Stefanou et al. [7]

- Analyzing student response to surveys on student outcomes relevant to lifelong learning in the diverse classroom environments

- Conducting focus groups with student to develop a deeper understanding of emergent themes in the student responses to instruction in the different course settings

- Conducting semi-structured, open-ended instructor interviews to develop a deeper understanding of the instructors' rationales for instructional decisions with respect to objectives associated with supporting student outcomes associated with lifelong learning

The results from this research will be a valuable resource for all engineering educators in helping their students develop lifelong learning skills to enable them to be successful in their careers.

\section{ACKNOWLEDGMENT}

This work is supported by the US National Science Foundation under Grant Nos. EEC-0835884, EEC-0835889, EEC-0835901, and EEC-0835911.

\section{REFERENCES}

[1] The Engineer of 2020: Visions of Engineering in the New Century. (National Academy Press (U.S.), Washington DC, 2004).

[2] Clough, G., Educating the Engineer of 2020: Adapting Engineering Education to the New Century. (National Academy of Engineering, Washington, DC, 2005).

[3] Criteria for Accrediting Engineering Programs, Accreditation Board for Engineering and Technology Engineering Accreditation Commission (2005). Available at http://www.abet.org/forms.shtml

[4] Litzinger, T., Wise, J., Lee, S., Bjorkund, S. (2003) “Assessing Readiness for Self $\bullet$ directed Learning”, Proceedings, ASEE Annual Conference and Exposition.

[5] Fowler, D., Maxwell, D., and Froyd, J., (2003) "Learning Strategy Growth Not What Expected After Two Years through Engineering curriculum", Proceeding, ASEE Annual Conference \& Exposition.

[6] Blumberg, B., "Evaluating the Evidence that Problem-Based Learners are Self-Directed Learners: A Review of the Literature," in D.H. Evensen and C.E. Hmelo, eds., Problem Based Learning: A Research Perspective on Learning Interactions, Mahwah, NJ: Erlbaum, 2000, pp. 199-226.

[7] Stefanou, C. R., K. C. Perencevich, M. DiCintio, and J. C. Turner, "Supporting Autonomy in the Classroom: Ways Teachers Encourage Student Decision Making and Ownership," Educational Psychologist $39297 \bullet 110$ (2004).

\section{AUTHOR INFORMATION}

John Chen, Associate Professor, Mechanical Engineering, California Polytechnic State University

Susan Lord, Coordinator and Professor, Electrical Engineering, University of San Diego

Katharyn Nottis, Associate Professor, Education, Bucknell University

Michael Prince, Professor, Chemical Engineering, Bucknell University

Candice Stefanou, Associate Professor, Education,

Bucknell University

Jonathan Stolk, Associate Professor, Mechanical

Engineering and Material Science, Olin College 